\title{
Peptide-Fluorophore Hydrogel as a Signal Boosting Approach in Rapid Detection of Cancer DNA
}

Jandl, Bernhard; Sedghiniya, Sima; Carstens, Annika; Astakhova, Kira

Published in:

ACS Omega

Link to article, DOI:

10.1021/acsomega.9b01586

Publication date:

2019

Document Version

Publisher's PDF, also known as Version of record

Link back to DTU Orbit

Citation (APA):

Jandl, B., Sedghiniya, S., Carstens, A., \& Astakhova, K. (2019). Peptide-Fluorophore Hydrogel as a Signal Boosting Approach in Rapid Detection of Cancer DNA. ACS Omega, 4(9), 13889-13895.

https://doi.org/10.1021/acsomega.9b01586

\section{General rights}

Copyright and moral rights for the publications made accessible in the public portal are retained by the authors and/or other copyright owners and it is a condition of accessing publications that users recognise and abide by the legal requirements associated with these rights.

- Users may download and print one copy of any publication from the public portal for the purpose of private study or research.

- You may not further distribute the material or use it for any profit-making activity or commercial gain

- You may freely distribute the URL identifying the publication in the public portal 


\title{
Peptide-Fluorophore Hydrogel as a Signal Boosting Approach in Rapid Detection of Cancer DNA
}

\author{
Bernhard Jandl, ${ }^{\dagger,}$ Sima Sedghiniya, ${ }^{\dagger, \S}$ Annika Carstens, ${ }^{\dagger, \|}$ and Kira Astakhova ${ }^{*}{ }^{\dagger}$ (i) \\ ${ }^{\dagger}$ Department of Chemistry, Technical University of Denmark, 206-207 Kemitorvet, 2800 Kgs Lyngby, Denmark \\ ${ }^{\ddagger}$ Institute of Applied Synthetic Chemistry, TU Wien (Vienna University of Technology), Getreidemarkt 9, 1060 Wien, Austria \\ ${ }^{\S}$ School of Chemistry, College of Science, University of Tehran, Tehran 14155-6455, Iran \\ "Department of Physics, Chemistry and Pharmacy, University of Southern Denmark, Campusvej 55, 5230 Odense M, Denmark
}

\author{
Supporting Information
}

\begin{abstract}
Cancer is a major health risk in the modern society that requires rapid, reliable, and inexpensive diagnostics. Because of the low abundance of cancer DNA in biofluids, current detection methods require DNA amplification. The amplification can be challenging; it provides only relative quantification and extends time and
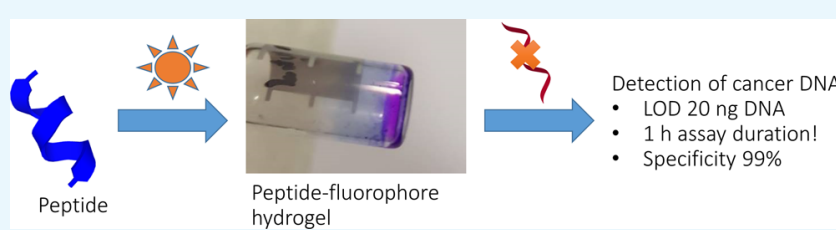
cost of an assay. Herein, we report a new oligonucleotide hybridization platform for amplification-free detection of human cancer DNA. Using a large PEG-capture probe allows rapid separation of the bound (mutant) versus unbound (wild type) DNA. Next, a supramolecular hydrogel forming peptide attached to a detection oligonucleotide probe serves as a signal amplification tool. Having screened multiple short peptides and fluorophores, we identified the system P1 + cyanine 3.5 that allows for sensitive quantitative detection of mutation L858R in EGFR oncogene. The peptide-fluorophore-based assay provides absolute target DNA quantification at the detection limit of 20 ng cancer DNA versus $>500 \mathrm{ng}$ for Cy3.5-labeled oligonucleotide in only 1 hour.
\end{abstract}

\section{INTRODUCTION}

Oncogenes are regions of normal human DNA that upon mutation drive cancer development and progression. ${ }^{1,2}$ Pointof-care (POC) approaches aim for detecting mutations in human oncogenes in a reliable and affordable way. ${ }^{1}$ Recent research on single nucleotide polymorphisms (SNP) in human oncogenes is now being actively translated into diagnostic solutions. However, DNA samples are subjected to polymerase-chain reaction (PCR) prior to SNP detection. This raises issues with standardization of PCR, target quantification, and inability to detect numerous SNPs such as KRAS G12D, and so forth. ${ }^{1,2}$ Besides predicting cancer, SNP in oncogenes is a valuable guide for treatment. Recurring target oncogenes include PIK3CA, FBXW7, EGFR, BRAF, and NRAS. ${ }^{3}$ Moreover, various resistance mechanisms were revealed by SNP profiling in single cancer cells, suggesting considerable resistance heterogeneity of tumor tissues. ${ }^{4}$

Performing amplification-free detection requires a signal boosting approach that would allow detecting cancer DNA with a required signal-to-noise ratio at ultra-low target amounts. 5 One way to achieve this was demonstrated by using fluorophore-labeled branched DNA. ${ }^{6,7}$ These labeled probes caused an increase of the signal by multiple fluorophores obtained in the received hybrids from cascade hybridization reactions. ${ }^{6,7}$ Another method involves the direct physical fluorescence amplification mechanism, based on origami DNA optical antennas. ${ }^{8}$ Origami DNA is capable of incorporating noble metal nanoparticles, leading to a plasmonic hotspot for fluorescent enhancement. ${ }^{9}$ Other amplification-free methods include SERS analysis, ${ }^{10}$ piezoelectric plate sensors, ${ }^{11}$ and Raman spectroscopy-based methods. ${ }^{12}$

Optical and electrochemical detection methods are promising approaches to achieve a sensitive and repeatable assay that is also robust and quick to use. ${ }^{13-16}$ Previously, we demonstrated an enzyme-free detection of cancer SNP using synthetic oligonucleotide probes and fluorescence microscopy. ${ }^{13}$ Although sensitive, this methodology requires a significant experimental effort and a confocal fluorescence microscopy equipment. Thus, techniques with simultaneous improvements toward high throughput and portability are still appealing. ${ }^{14}$

Fluorescent readouts are capable of giving rapid and quantitative results. ${ }^{13}$ Therefore, fluorescence is implemented in various diagnostic tools used in research and clinical practice. ${ }^{17}$ Latest developments in this field aim at multiplexed fluorescence readouts by using time responses of color-coded signals. ${ }^{18}$ Especially in multiplex detection, assay artifacts due to interference of probes or fluorophores make it important to select the appropriate fluorophore and assay conditions. ${ }^{19}$

Generally, scaffolding along biomolecules is an attractive paradigm for signal boosting that has been explored in, for

Received: May 30, 2019

Accepted: August 2, 2019

Published: August 16, 2019 
example, DNA origami and DNA-fluorophore signal boosting. ${ }^{8,13}$ Oligo- and polypeptides is another class of biomolecules that can form diverse nanostructures with fluorophores. Peptides are cheaper reagents compared to large DNA, and their self-assembly is faster than DNA. ${ }^{20-23}$ As a drawback, the formation of peptide nanostructures is more difficult to predict compared to DNA. Nevertheless, selfassembly of rationally designed peptide sequences is emerging as a potential route for peptide hydrogel design with promising applications in biosensing. ${ }^{21-23}$ Researchers have successfully designed several supramolecular hydrogels based on peptides and peptide conjugates with oligonucleotides or polymers. ${ }^{24-26}$ It was shown that the peptide sequence is key to form a hydrogel, and that peptides can be ideally engineered to form hydrogels with desired properties. ${ }^{27,28}$ The knowledge obtained from several peptide sequences and their conjugates provides an useful insight into the formation mechanism of the gel. $^{24-28}$ Moreover, the conditions at which gelation takes place including individual and collective features of each amino acid have been described. ${ }^{29-31}$

Additionally, fluorescent hydrogels have gained research concern because of their practical applications as a convenient tracer in biomedical engineering. ${ }^{32,33}$ Multiple fluorescencebased hydrogels have been developed recently by either chemical or physical immobilization of fluorophores, for biosensing, thermoresponsive sensing, and hydrogel degradation tracking. ${ }^{34-36}$ Nevertheless, reported routes for attaching fluorophores to hydrogels have limitations, mainly because of the complexity of the hydrogel microenvironment and often unpredictable interactions with analytes. ${ }^{37,38}$ As a result, there is still an unmet need in new robust methodologies for preparation and applying fluorescent hydrogels. ${ }^{37,38}$

In this work, we aimed at a POC detection for human oncogene EGFR, using a peptide-fluorophore signal boosting approach. Our hypothesis to be tested was that cancer DNA can be detected by a specific hybridization probe conjugated with a peptide sequence that can form a hydrogel. We selected a sequential hybridization methodology, along with an optical read-out of a fluorophore-peptide hydrogel, as a robust and accessible method for POC applications. ${ }^{13,16}$

\section{RESULTS AND DISCUSSION}

Initially, we performed a screening of peptide candidates, aiming at their following properties: (1) ability to form a hydrogel in aqueous media; (2) non-quenching inclusion of fluorophores into the gel; (3) linear dependence of the fluorescence signal to the amount of the added peptide. Based on existing literature, ${ }^{32-38}$ short charged peptides have a high propensity for gelation in aqueous media. We included three peptide candidates in this study (Figure 1; Supporting Information, Tables S1 and S2). Among a broad range of available fluorophores, we used Cy3.5, AlexaFluor547, and anthracene (AC), as shown in Figure 1C. The rationale behind the choice of these fluorophores was their high quantum yield and confirmed interactions with biomolecules. ${ }^{39,40}$ Azide functionalities were incorporated into the fluorophores to provide an ability of covalent conjugation to a control probe, described below. However, having an azide is not critical for hydrogel formation and can be omitted. ${ }^{37,38}$

The procedure for preparation of hydrogels included mixing of an aqueous solution of peptide with a solution of fluorophore in dimethylsulfoxide (DMSO) and leaving the mixture for over $1-48 \mathrm{~h}$ at room temperature. The quality of a)

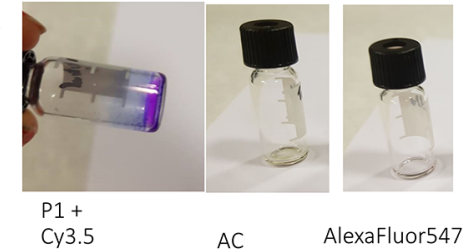

b)
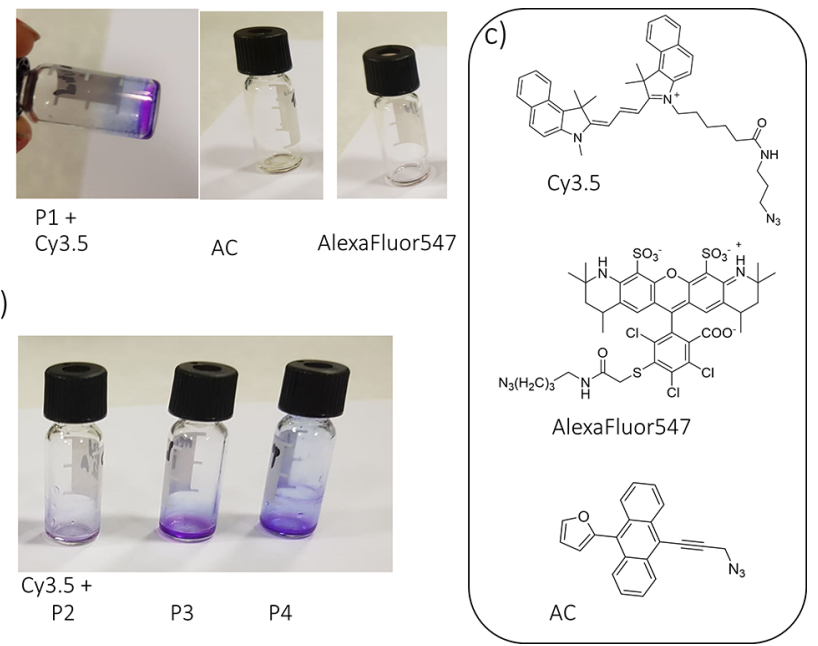

Figure 1. Hydrogel formation by selected peptides: (a) P1 with different dyes; (b) Cy3.5 with P2-P4; (c) Chemical structures of fluorophores used in this study. Peptide sequences were as follows: written in $\mathrm{C} \rightarrow \mathrm{N}$ direction: P1, GGKKRRQKGR; P2, RKKRRRRR; P3, GGAAGGAY; P4, YGGAAGGK.

liquid $\rightarrow$ hydrogel transition, if hydrogel formation occurred, was rated, and each sample was categorized with one out of three possible statuses: no gel, gelish, and gel. These categories were given based on the viscosity of the liquid/gel and the visible behavior of the sample when mechanical forces such as spinning, tending, and slight shaking were applied. By measuring gelation efficiency at different time points, we also studied kinetics of hydrogel formation and fluorescence response of the applied dyes to the amount of peptide (Supporting Information; Figures S1 and S2).

Figure 1 shows hydrogel formation by best-performing candidates. The complete results of the peptide-fluorophore hydrogel formation screening and their hydrogel formation rating can be taken from Table S2, Supporting Information. All peptides formed a hydrogel under the applied conditions. Upon adding fluorophores, P2 and P4 had the best results; whereas P1 formed a hydrogel only with Cy3.5 (Figure 1; Supporting Information, Table S2). Notably, peptide P3 showed no hydrogel formation, most likely because of its hydrophobic properties. Adding fluorophores slightly slowed down the gelation for P1, P2, and P4, especially in the case of AlexaFluor547. Moreover, the fluorescence of AlexaFluor547 was completely quenched by adding all the peptides (Figure 1A).

Fast formation of a peptide hydrogel is a key feature for successful POC diagnostics. We investigated the kinetics of hydrogel formation and optimized the conditions to secure a complete gel formation in $1.5 \mathrm{~h}$ (Supporting Information; Figures S1 and S2). In this experiment, we followed the gelation by fluorescence response of $\mathrm{Cy} 3.5$ which was added to the concentrated solution of the peptide in $1 \times$ phosphate buffered saline (PBS), $110 \mathrm{mM}\left[\mathrm{Na}^{+}\right], \mathrm{pH}$ 7.0. Our data show a $33 \%$ quenching of Cy3.5 fluorescence during first $40 \mathrm{~min}$ after adding the peptide and a dye to the media; after $1.5 \mathrm{~h}$, the fluorescence response does not change. Based on this result, and on a visible behavior of the samples, we concluded that the hydrogel formation for $\mathrm{P} 1+\mathrm{Cy} 3.5$ has been complete in $1.5 \mathrm{~h}$. In contrast, for $\mathrm{P} 2$ and $\mathrm{P} 4$, gelation took as long as $12 \mathrm{~h}$ upon adding Cy3.5 (Figure S2, Supporting Information). 

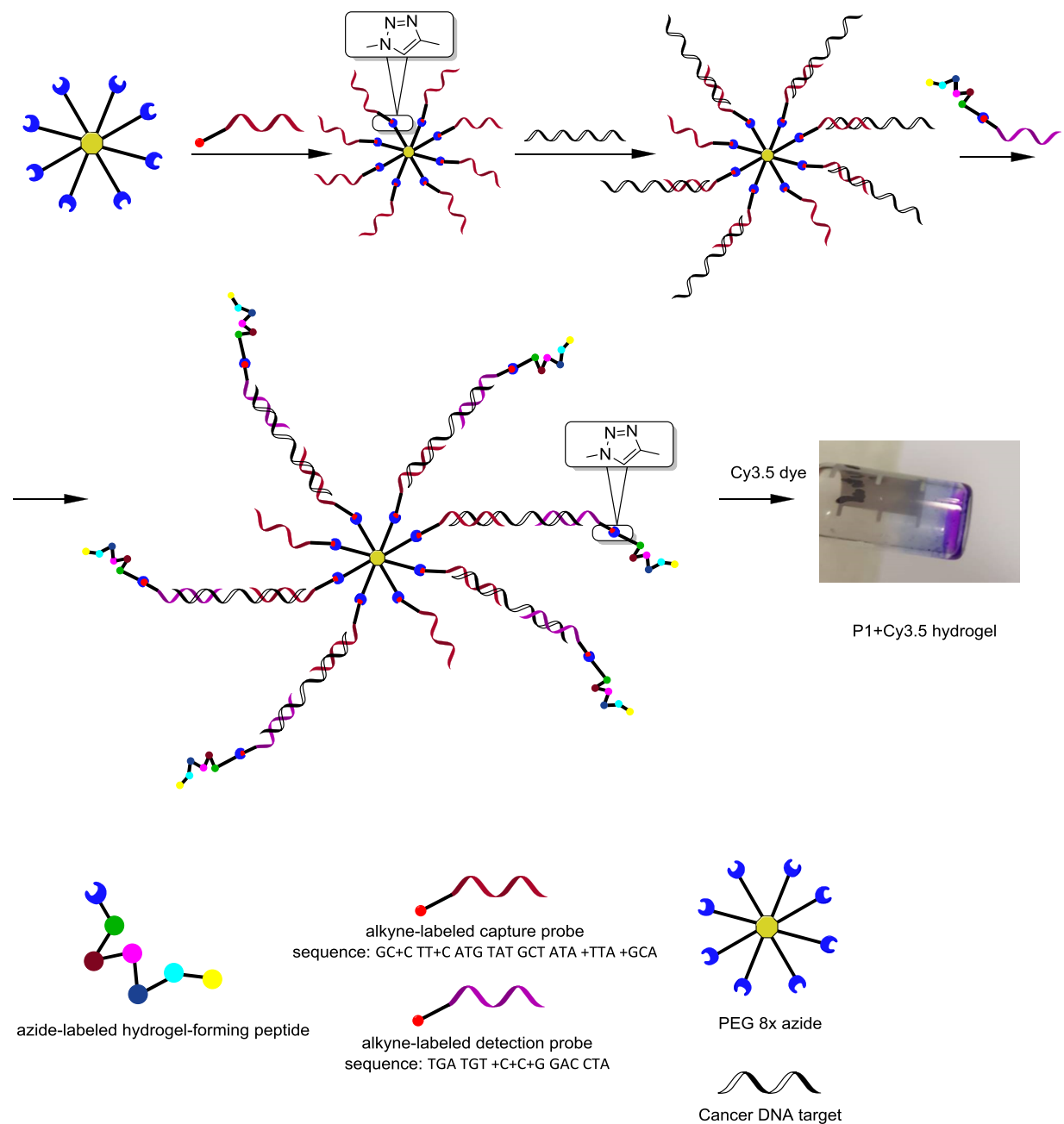

Figure 2. Scheme of P1 + Cy3.5 amplification-free assay and sequences of its key components. Azide-modified $\mathrm{P} 1$ sequence: $\mathrm{N}_{3}\left(\mathrm{CH}_{2}\right)_{5} \mathrm{C}(\mathrm{O})$ GGKKRRQKGR-NH ${ }_{2}$. LNA = locked nucleic acid, indicated with a plus in front of a nucleotide letter. Molecular weight cutoff value of $100 \mathrm{kDa}$ has been selected based on the calculated mass for PEG-capture probe:target complex bound to at least one cancer DNA molecule over $1000 \mathrm{nt}$ long.

Next, we focused on optimizing the ratio of the peptide to fluorophore in order to achieve the highest brightness at the lowest peptide amount. The data shown in Chart S2, Supporting Information, reveal that the most sensitive system is $\mathrm{P} 1$ and $\mathrm{Cy} 3.5$. In the case of $\mathrm{AC}$, no clear concentration dependence of fluorescence response appeared (Supporting Information, Chart S2). Based on these data, we selected the system $\mathrm{P} 1+\mathrm{Cy} 3.5$ in molar ratio 1:10 as the most promising for further POC assays.

We proceeded with developing a detection methodology for cancer DNA. The design of the assay is shown in Figure 2. A capture probe is attached to PEG $8 \times$. According to our idea, PEG would make large size products with cancer DNA, and in that way, a bound capture:cancer DNA can be easily separated from unbound DNA (wild type) by size exclusion. ${ }^{41}$ The detection probe is complementary to the upstream region of the capturing sequence and contains a terminally attached hydrogel forming peptide P1. We selected EGFR oncogene for the pilot study, given its high importance in monitoring multiple types of cancer including breast cancer and melanoma, as well as its recently confirmed role in hyperactivation of cancer progression as a response to immunotherapy. $^{42,43}$
For the assay, the detection and capture probes have been designed using publicly available NCBI data and our previously reported probe uniqueness analysis. ${ }^{13}$ Following our previous studies, we enriched the oligonucleotides with affinity and specificity enhancing locked nucleic acids. ${ }^{13}$ Oligonucleotide 1 (ON1) has been purchased as a $5^{\prime}$-amino-modified precursor and converted to alkyne-modified $\mathrm{ON}^{\prime}$ by reaction with STP alkyne reagent. $3^{\prime}$-Alkyne modified ON2 has been synthesized in house, using the automated solid-phase phosphoramidite method. Oligonucleotides $\mathrm{ON}^{\prime}$ and $\mathrm{ON} 2$ have been characterized by IC HPLC and MALDI-TOF MS (Supporting Information; Table S3, Figure S3).

Commercially available PEG $8 \times$ azide has been conjugated with alkyne-modified capturing probe $\mathrm{ON}^{\prime}$ under standard CuAAC click conditions. ${ }^{44}$ The product has been purified by NAP-5 gel filtration and characterized by HPLC, fluorometry titration with complementary DNA, and by denaturing PAGE. HPLC confirmed full conversion of $\mathrm{ON}^{\prime}$ after the click reaction with PEG $8 \times$ (Supporting Information, Figure S4); by adding a DNA complement and a double-stranded DNA binding fluorophore Eva Green, we confirmed that all the attached strands in $\mathrm{ON} 3$ were able to form a duplex with the target DNA (Supporting Information, Chart S4). Finally, 
denaturing PAGE stained with SybrGreen confirmed a product length of approx. $130 \mathrm{nt}$ (Supporting Information, Chart S5). This corresponds to attachment of six oligonucleotides ON1 to PEG $8 \times$.

Knowing the number of attached capture probes per PEG core allowed us to establish a molecular weight cutoff (MWCO) value for DNA binding assay. Thus, the molecular weight of the PEG-oligonucleotide conjugate has been estimated as $56 \mathrm{kDa}$. Upon binding at least one fragment of genomic DNA of a size over $1000 \mathrm{nt}$, the weight of the complex would exceed $100 \mathrm{kDa}$. Therefore, a MWCO of 100 $\mathrm{kDa}$ has been applied in the assay described below.

Azido-derivative of $\mathrm{P} 1$ has been conjugated under a similar CuAAC procedure ${ }^{44}$ with precursor ON2. As a control, we conjugated $\mathrm{ON} 2$ with $\mathrm{Cy} 3.5$ azide; all the products have been characterized by IC HPLC and MALDI-TOF (Supporting Information, Table S3, Figure S5).

Next, we conducted a genotyping assay and benchmarked it to mono-Cy3.5-labeled detection probe and quantitative PCR (qPCR; Figure 3 and Supporting Information, section 3). For

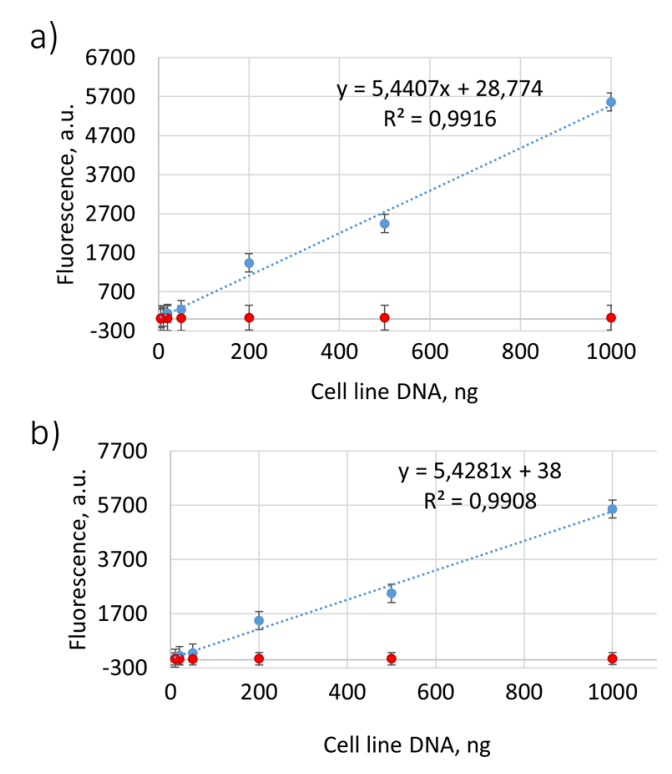

Figure 3. Amplification-free detection of mutated EGFR DNA from cancer cells: LOD determination and control with wild-type DNA for P1 + Cy3.5 (a), vs Cy3.5-labeled detection probe (b). The data for mutated vs wild-type DNA are shown in blue and red, respectively. Excitation/emission wavelengths: $580 \mathrm{~nm} / 610 \mathrm{~nm}$.

the assay, we used EGFR-mutated DNA from human cancer cells. The DNA sample has been purified by a Qiagen DNA work up kit, followed by digestion with EcoRI. This provided DNA fragments of $7000 \mathrm{bp}$ in average, confirmed by QiaExpert analysis. The detection assay has been conducted in a 96-well format, which is suitable for conventional microplate processing and read-out equipment. At the selected concentration, a signal for free Cy3.5 was $445 \pm 2$ a.u. When the assay was conducted with a detection probe lacking a peptide, a background fluorescence signal of $19 \pm 2$ a.u was recorded (data shown in Figure S6). A free Cy3.5 dye has been removed by a triple washing procedure; the complete removal of the dye has been confirmed by fluorometry analyses of the washes (data not shown). Along with this experiment, a series of controls has been performed, including spike-in of wild type DNA into the EGFR sample, adding unmodified P1 to speed up the gelation, and qPCR. These data can be found in Supporting Information, Figures S7 and S8.

We observed a concentration-dependent sensing of EGFR DNA by the P1 + Cy3.5 system, with a limit of target detection (LOD) of only $20 \mathrm{ng}$ cancer DNA (550 pM), versus >500 ng (15 nM) for Cy3.5-labeled oligonucleotide (Figure 3).

The LOD for the peptide hydrogel assay is similar to conventional qPCR and is 5-fold lower than for DNA microarrays. ${ }^{45}$ The LOD of $550 \mathrm{pM}$ is also similar to DNA fluorophore nanostructures reported before, when a conventional fluorometry has been applied. ${ }^{5}$ The LOD of our method can be further decreased by applying advanced optical solutions, reaching previously reported low femtomolar for a DNA-Eva Green complex. ${ }^{5,13}$

The detection procedure for our assay is 2-fold faster than for qPCR (Supporting Information, Figure S8). ${ }^{3}$ Moreover, the estimated cost for the peptide hydrogel assay is USD 0.2, versus 0.89 USD per reaction for GPCR (in house data). Last, the assay does not require handling an enzyme, dNTP, and other sensitive reagents, which makes it easier to carry out. ${ }^{3}$

To verify the assay specificity, we used the HMC cell line that does not contain a mutated EGFR. P1 + Cy3.5 assay showed $99 \%$ specificity for the mutated EGFR over wild-type DNA (Figure 3). We also performed a spike-in experiment, where EGFR DNA was mixed with HMC at different ratios. Using the P $1+\mathrm{Cy} 3.5$ hybridization assay, detection down to $20 \%$ EGFR in wild-type HMC DNA has been achieved (Supporting Information; Figure S7).

The multivalence of PEG capture probe increases the probability of cross-binding between DNA strands. This could lead to changes in the calibration curve at increasing DNA target concentrations. Although not observed for the doublestranded DNA target used herein (Figure 3), a cross-binding would be a considerable risk for long single-stranded DNA targets. This needs to be taken into consideration, and if it

\section{Table 1. Results of the MD Study in DINC2.0}

\begin{tabular}{|c|c|c|c|c|c|}
\hline peptide & fluorophore & energy of the dimer, $\mathrm{kcal} / \mathrm{mol}$ & RMSD, Å (dimer) & energy_dye docking, $\mathrm{kcal} / \mathrm{mol}$ & RMSD, Å, peptide-fluorophore \\
\hline \multirow[t]{3}{*}{ P1 } & Сy3.5 & -3.9 & 7.1 & -5.1 & 6.0 \\
\hline & AF547 & & & -5.9 & 0.2 \\
\hline & $\mathrm{AC}$ & & & -5.0 & 7.8 \\
\hline \multirow[t]{3}{*}{$\mathrm{P} 2$} & Су3.5 & -3.8 & 6.8 & -5.2 & 4.7 \\
\hline & AF547 & & & -5.6 & 3.0 \\
\hline & $\mathrm{AC}$ & & & -4.8 & 6.2 \\
\hline P3 & Сy3.5 & -4.1 & 3.4 & -4.5 & 4.0 \\
\hline P4 & Cy3.5 & -3.8 & 5.0 & -4.5 & 3.7 \\
\hline
\end{tabular}

${ }^{a}$ RMSD is an average value for three lowest energy structures obtained in docking studies. 
occurs, a buffer composition could be adjusted to more denaturing conditions.

As another control, we conducted the assay with EGFR DNA and P1 + Cy3.5, in the presence of additional P1. We wondered if having an excess of free peptide could promote hydrogel formation, leading to higher fluorescence and lower LOD. Indeed, adding 5-10 $\mathrm{nM}$ free P1 promoted the gelation which now took as little as $30 \mathrm{~min}$. However, when adding over $10 \mathrm{nM}$ free $\mathrm{P} 1$, the separation procedure for non-bound DNA and peptide has been complicated and an increased falsepositive signal has been observed (data not shown).

We assessed reproducibility of the assay by a series of three repeated independent measurements, in the DNA target concentration range 20-200 ng. The measurements were carried out for EGFR DNA by our assay and qPCR. The calculated coefficient of variation $(\mathrm{CV})$ for the peptide hydrogel assay was $1.5-2.5 \%$, and it increased upon decreased DNA target amount, which is expected. The observed CV was qPCR was $\sim 2.6$ fold higher in the range 3.7-6.7\% (Supporting Information; Table S4).

To investigate the structure of peptide-fluorophore hydrogels, we performed a series of molecular dynamics (MD) studies (Supporting Information, section 5; Table 1, Figures S9-S20). In doing this, we used RPBS PEPFOLD 3 and DINC 2.0, which are suitable force fields for analyzing peptide folding and interactions. ${ }^{46,47}$ Our approach to building the structural model for peptide-fluorophore hydrogel included 4 steps: (1) predicting the $3 \mathrm{D}$ structure of individual peptides; (2) studying self-assembly of each peptide; (3) simulating interactions of individual peptides with fluorophores; and (4) building a complete model for the peptide-fluorophore interaction within a hydrogel.

Our MD results are shown in Table 1 and in Figures S9S20, Supporting Information. Among all studied peptides, P1 forms the most well-defined helix (Figure S9). P2 also forms a helical motif vs. hairpin formation predicted for P3 and P4 (Supporting Information, Figures S10-S12). P1-P4 have almost similar free energies predicted for dimer structures; however, in $\mathrm{P} 1$ and $\mathrm{P} 2$, the average distance between two peptide chains is longer, 6.8-7.1 $\AA$ versus $3.4-5.0 \AA$ for P3P4 (Table 1). This correlates with a lower energy for docking products of $\mathrm{P} 1-\mathrm{P} 2$ with fluorophores vs. $\mathrm{P} 3-\mathrm{P} 4$. According to the literature, having a cavity of $>5 \AA$ is a structural requirement for embedding small molecules into peptide assemblies. ${ }^{48,49}$ Therefore, $\mathrm{P} 1$ and $\mathrm{P} 2$ are the most potent candidates, according to $\mathrm{MD}$, for interaction with fluorophores (Figure 4A).

Close proximity of a fluorophore to a biomolecule can be caused by active hydrogen bond formation. ${ }^{50}$ This seems to be the case for polar group-rich Cy3.5 and AlexaFluor547, compared to the longer distance between the peptides to nonpolar AC (Supporting Information, Figures S15 and S18 vs Figures S13, S14, S16, S17, S19, and S20). However, a close proximity of a fluorophore to the biomolecule might lead to quenching of fluorescence, for example, by the Dexter mechanism or photo-induced electron transfer. ${ }^{51}$ To account for this, we conducted a series of titrations for fluorophores Cy3.5 and AC, with peptides P1 and P3 (Supporting Information, section 6). A fluorophore has been mixed with a peptide in different ratios, and the resulting hydrogel has been analyzed by vis absorbance (Figure 4B; Figure S21), excitation (Figure S22), and emission spectra (Figure S23). a)

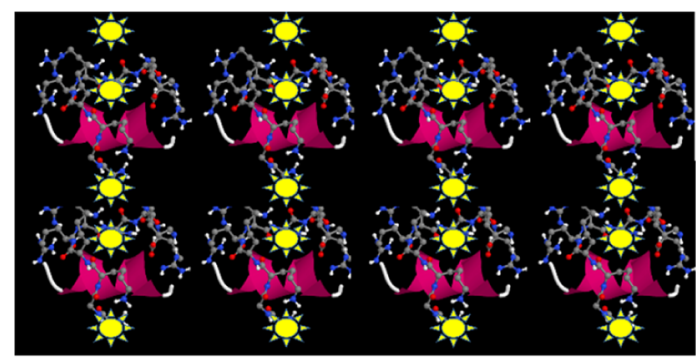

b)

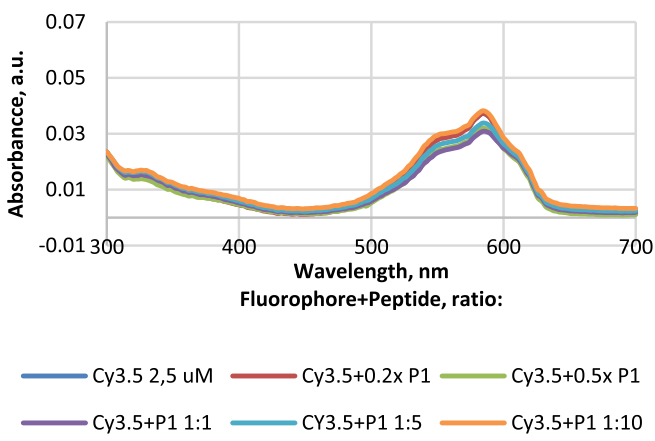

Figure 4. Structural model (a) and UV-Visible absorbance (b) for P1 + Cy3.5 hydrogel. The model has been obtained in PEPFOLD 3/ DINC2.0 MD and docking environment. Cy3.5 is shown in yellow. Computed $\Delta G$ values for the model are given in Table 1. Absorbance spectra have been recorded in $0.5 \%$ DMSO-1× PBS buffer, $\mathrm{pH} 7.0$, using $2.5 \mu \mathrm{M}$ Cy3.5 and different molar ratios of $\mathrm{P} 1$.

UV-Visible absorbance spectra of $\mathrm{Cy} 3.5$ are weakly changed by adding P1/P2 (Figure 4B). This is on the contrary to AC, which exhibits quenching of absorbance and a $4 \mathrm{~nm}$ blue shift of absorbance maxima upon adding P1 (Figure S21). Excitation spectra for both Cy3.5 and AC are slightly quenched upon adding $\mathrm{P} 1 / \mathrm{P} 3$, with similar positions of maxima to vis absorbance spectra. Fluorescence emission reveals an active excimer formation by AC, with emission maxima at 530 and $585 \mathrm{~nm}$, also in the presence of P1 (Supporting Information, Figure S23). Fluorescence intensity of Cy3.5 is poorly affected by adding P1 and is slightly quenched in the presence of P3. For Cy3.5 + P1, fluorescence maxima are bathochromically shifted by $3 \mathrm{~nm}$ compared to free Cy3.5. These results point on two important structural features of the studied systems which also fit with the results of MD studies: (1) AC actively interacts with itself by forming an excimer, and it poorly interacts with $\mathrm{P} 1$; (2) Cy3.5 is incorporated into hydrogel, most likely, by weak hydrogen binding with $\mathrm{P} 1$; (3) upon hydrogel formation, Cy3.5 is positioned into a more polar environment compared to the free dye, leading to a bathochromic shift of emission maxima. ${ }^{51}$

Altogether, our MD data and optical assays confirm favorable properties of the P1 + Cy3.5 system for hydrogel formation, accompanied by high fluorescence intensity of Cy3.5, as a result of several structural features. First, P1 folds into a helical structure and self-assembles. Second, P1 assembly creates a series of cavities for embedding Cy3.5. Third, hydrogen bonding retains Cy3.5 in a complex with P1. Last, Cy3.5 forms relatively weak hydrogen bonds with P1, leading to its high fluorescence intensity being remained in the hydrogel (Figure 4A). 


\section{CONCLUSIONS}

In conclusion, we developed an amplification-free detection method for human cancer DNA. The method is based on size exclusion of mutant DNA bound to the PEG-capture probe, and on detection by forming a fluorophore-peptide gel. As a proof of principle, we successfully detected EGFR oncogene at an amount down to $20 \mathrm{ng}$ total DNA, with specificity over $99 \%$. However, other oncogenes can be tested by our approach as well. Our method is simple, fast, and relatively inexpensive, opening up exciting opportunities for POC applications. Our structural model explains how the selected peptide interacts with Cy3.5 fluorophore and might open new paths for developing amplification-free diagnostic systems.

\section{ASSOCIATED CONTENT}

\section{S Supporting Information}

The Supporting Information is available free of charge on the ACS Publications website at DOI: 10.1021/acsomega.9b01586.

Detailed experimental procedures and additional figures; sequences of peptides and oligonucleotides used in this study; synthetic procedures, reaction work-up and product characterization details; hybridization assay, controls, PCR, and computing and optical studies (PDF)

\section{AUTHOR INFORMATION}

\section{Corresponding Author}

*E-mail: kiraas@kemi.dtu.dk.

\section{ORCID}

Kira Astakhova: 0000-0003-4878-0301

Notes

The authors declare no competing financial interest.

\section{ACKNOWLEDGMENTS}

This work was supported by the Villum Fonden award no. 13152, and Jorck Research Prize, award no. 40934. We acknowledge Prof. Dr, K. Jensen, University of Copenhagen, for providing with azide-modified peptide $\mathrm{P} 1$, and Lumiprobe $\mathrm{GmbH}$ for providing with Cy3.5 fluorophore, CuAAC and STP reagents.

\section{REFERENCES}

(1) Finotti, A.; Allegretti, M.; Gasparello, J.; Giacomini, P.; Spandidos, D.; Spoto, G.; Gambari, R. Liquid biopsy and PCR-free ultrasensitive detection systems in oncology. Int. J. Oncol. 2018, 53, $1395-1434$.

(2) Hiom, S. C. Diagnosing cancer earlier: Reviewing the evidence for improving cancer survival. Br. J. Cancer 2015, 112, S1-S5.

(3) (a) Dahse, R.; Berndt, A.; Kosmehl, H. PCR-based testing for therapy-related EGFR mutations in patients with non-small cell lung cancer. Anticancer Res. 2008, 28, 2265-2270. (b) Shin, S.; Kim, J.; Kim, Y.; Cho, S.-M.; Lee, K.-A. Assessment of real-time PCR method for detection of EGFR mutation using both supernatant and cell pellet of malignant pleural effusion samples from non-small-cell lung cancer patients. Clin. Chem. Lab. Med. 2017, 55, 1962-1969.

(4) Yu, S.; Liu, D.; Shen, B.; Shi, M.; Feng, J. Immunotherapy strategy of EGFR mutant lung cancer. Am. J. Cancer Res. 2018, 8, 2106-2115.

(5) Astakhova, K. Toward non-enzymatic ultrasensitive identification of single nucleotide polymorphisms by optical methods. Chemosensors 2014, 2, 193-206.
(6) Collins, M.; Irvine, B.; Tyner, D.; Fine, E.; Zayati, C.; Chang, C.; Horn, T.; Ahle, D.; Detmer, J.; Shen, L. P. A branched DNA signal amplification assay for quantification of nucleic acid targets below 100 molecules/ml. Nucleic Acids Res. 1997, 25, 2979-2984.

(7) Horn, T.; Chang, C. A.; Urdea, M. S. Chemical synthesis and characterization of branched oligodeoxyribonucleotides (BDNA) for use as signal amplifiers in nucleic acid quantification assays. Nucleic Acids Res. 1997, 25, 4842-4849.

(8) Darvill, D.; Centeno, A.; Xie, F. Plasmonic fluorescence enhancement by metal nanostructures: Shaping the future of bionanotechnology. Phys. Chem. Chem. Phys. 2013, 15, 15709-15726.

(9) Ochmann, S. E.; Vietz, C.; Trofymchuk, K.; Acuna, G. P.; Lalkens, B.; Tinnefeld, P. Optical nanoantenna for single moleculebased detection of Zika Virus nucleic acids without molecular multiplication. Anal. Chem. 2017, 89, 13000-13007.

(10) Wu, L.; Garrido-Maestu, A.; Guerreiro, J. R. L.; Carvalho, S.; Abalde-Cela, S.; Prado, M.; Diéguez, L. Amplification-free SERS analysis of DNA mutation in cancer cells with single-base sensitivity. Nanoscale 2019, 11, 7781-7789.

(11) Kirimli, C.; Lin, S.; Su, Y.-H.; Shih, W.-H.; Shih, W. Y. In Situ, Amplification-free double-stranded mutation detection at 60 copies/ $\mathrm{ml}$ with thousand-fold wild type in urine. Biosens. Bioelectron. 2018, $119,221-229$.

(12) Turner, A. P. F. Biosensors: Sense and sensibility. Chem. Soc. Rev. 2013, 42, 3184-3196.

(13) Miotke, L.; Maity, A.; Ji, H.; Brewer, J.; Astakhova, K. Enzymefree detection of mutations in cancer DNA using synthetic oligonucleotide probes and fluorescence microscopy. PLoS One 2015, 10, No. e0136720.

(14) Astakhova, I. K.; Samokhina, E.; Babu, B. R.; Wengel, J. Novel (phenylethynyl)pyrene-LNA constructs for fluorescence SNP sensing in polymorphic nucleic acid targets. ChemBioChem 2012, 13, 15091519.

(15) Astakhova, I. K.; Santhosh Kumar, T.; Campbell, M. A.; Ustinov, A. V.; Korshun, V. A.; Wengel, J. Branched DNA nanostructures efficiently stabilised and monitored by novel pyreneperylene 2 '- $\alpha$-l-amino-LNA FRET pairs. Chem. Commun. 2013, 49, 511-513.

(16) Astakhova, I. K.; Pasternak, K.; Campbell, M. A.; Gupta, P.; Wengel, J. A locked nucleic acid-based nanocrawler: Designed and reversible movement detected by multicolor fluorescence. J. Am. Chem. Soc. 2013, 135, 2423-2426.

(17) Grompe, M. The rapid detection of unknown mutations in nucleic acids. Nat. Genet. 1993, 5, 111-117.

(18) Yang, S.; Rothman, R. E. PCR-based diagnostics for infectious diseases: Uses, limitations, and future applications in acute-care settings. Lancet Infect. Dis. 2004, 4, 337-348.

(19) Nishimura, T.; Ogura, Y.; Tanida, J. Multiplexed fluorescence readout using time responses of color coded signals for biomolecular detection. Biomed. Opt. Express 2016, 7, 5284-5293.

(20) Chai, Q.; Jiao, Y.; Yu, X. Hydrogels for biomedical applications: Their characteristics and the mechanisms behind them. Gels 2017, 3, 6.

(21) Dasgupta, A.; Mondal, J. H.; Das, D. Peptide hydrogels. RSC Adv. 2013, 3, 9117-9149.

(22) Li, Y.; Wang, F.; Cui, H. Peptide-based supramolecular hydrogels for delivery of biologics. Bioeng. Transl. Med. 2016, 1, 306322.

(23) Loic, S. Amino acids modification to improve and fine-tune peptide-based hydrogels. Amino Acid-New Insights And Roles in Plant and AnimalAmino Acids Modification to Improve and Fine-Tune PeptideBased Hydrogels; InTechOpen, 2017.

(24) Jayawarna, V.; Ali, M.; Jowitt, T. A.; Miller, A. F.; Saiani, A.; Gough, J. E.; Ulijn, R. V. Nanostructured Hydrogels for ThreeDimensional Cell Culture Through Self-Assembly of Fluorenylmethoxycarbonyl-Dipeptides. Adv. Mater. 2006, 18, 611-614.

(25) Li, X.; Kuang, Y.; Lin, H.-C.; Gao, Y.; Shi, J.; Xu, B. Supramolecular nanofibers and hydrogels of nucleopeptides. Angew. Chem., Int. Ed. 2011, 50, 9365-9369. 
(26) Li, X.; Du, X.; Gao, Y.; Shi, J.; Kuang, Y.; Xu, B. Supramolecular hydrogels formed by the conjugates of nucleobases, Arg-Gly-Asp (RGD) peptides, and glucosamine. Soft Matter 2012, 8, 7402-7407.

(27) Hartgerink, J. D.; Beniash, E.; Stupp, S. I. Self-assembly and mineralization of peptide-amphiphile nanofibers. Science 2001, 294, $1684-1688$.

(28) Cui, H.; Webber, M. J.; Stupp, S. I. Self-assembly of peptide amphiphiles: From molecules to nanostructures to biomaterials. Biopolymers 2010, 94, 1-18.

(29) Jing, X.; Kasimova, M. R.; Simonsen, A. H.; Jorgensen, L.; Malmsten, M.; Franzyk, H.; Foged, C.; Nielsen, H. M. Interaction of peptidomimetics with bilayer membranes: Biophysical characterization and cellular uptake. Langmuir 2012, 28, 5167-5175.

(30) Klok, H.-A. Peptide/Protein-Synthetic Polymer Conjugates:Quo Vadis. Macromolecules 2009, 42, 7990-8000.

(31) Hamley, I. W. PEG-Peptide Conjugates. Biomacromolecules 2014, 15, 1543-1559.

(32) Duchardt, F.; Fotin-Mleczek, M.; Schwarz, H.; Fischer, R.; Brock, R. A Comprehensive Model for the Cellular Uptake of Cationic Cell-penetrating Peptides. Traffic 2007, 8, 848-866.

(33) Di Pisa, M.; Chassaing, G.; Swiecicki, J.-M. Translocation mechanism(s) of cell-penetrating peptides: Biophysical studies using artificial membrane bilayers. Biochemistry 2014, 54, 194-207.

(34) Fernandez-Carneado, J.; Kogan, M. J.; Van Mau, N.; Pujals, S.; Lopez-Iglesias, C.; Heitz, F.; Giralt, E. Fatty acyl moieties: Improving pro-rich peptide uptake inside HeLa cells. J. Pept. Res. 2005, 65, 580590.

(35) Wollack, J. W.; Zeliadt, N. A.; Mullen, D. G.; Amundson, G.; Geier, S.; Falkum, S.; Wattenberg, E. V.; Barany, G.; Distefano, M. D. Multifunctional prenylated peptides for live cell analysis. J. Am. Chem. Soc. 2009, 131, 7293-7303.

(36) Åmand, H. L.; Boström, C. L.; Lincoln, P.; Nordén, B.; Esbjörner, E. K. Binding of cell-penetrating penetratin peptides to plasma membrane vesicles correlates directly with cellular uptake. Biochim Biophys Acta Biomembr. 2011, 1808, 1860-1867.

(37) Birch, D.; Christensen, M. V.; Staerk, D.; Franzyk, H.; Nielsen, H. M. Fluorophore labeling of a cell-penetrating peptide induces differential effects on its cellular distribution and affects cell viability. Biochim Biophys Acta Biomembr. 2017, 1859, 2483-2494.

(38) Hedegaard, S. F.; Derbas, M. S.; Lind, T. K.; Kasimova, M. R.; Christensen, M. V.; Michaelsen, M. H.; Nielsen, H. M. Fluorophore labeling of a cell-penetrating peptide significantly alters the mode and degree of biomembrane interaction. Sci. Rep. 2018, 8, 6327.

(39) Nåbo, L. J.; Madsen, C. S.; Jensen, K. J.; Kongsted, J.; Astakhova, K. Ultramild protein-mediated click chemistry creates efficient oligonucleotide probes for targeting and detecting nucleic acids. ChemBioChem 2015, 16, 1163-1167.

(40) Smidlehner, T.; Rožman, A.; Piantanida, I. Advances in Cyanine - Amino Acid Conjugates and peptides for sensing of DNA, RNA and protein structures. Curr. Protein Pept. Sci. 2019, 30. DOI: $10.2174 / 1389203720666190513084102$.

(41) Broguiere, N.; Husch, A.; Palazzolo, G.; Bradke, F.; Madduri, S.; Zenobi-Wong, M. Macroporous hydrogels derived from aqueous dynamic phase separation. Biomaterials 2019, 200, 56-65.

(42) Bylicki, O.; Paleiron, N.; Margery, J.; Guisier, F.; Vergnenegre, A.; Robinet, G.; Auliac, J.-B.; Gervais, R.; Chouaid, C. Targeting the PD-1/PD-L1 immune checkpoint in EGFR-mutated or ALK-translocated non-small-cell lung cancer. Target Oncol 2017, 12, 563-569.

(43) Chen, N.; Fang, W.; Zhan, J.; Hong, S.; Tang, Y.; Kang, S.; Zhang, Y.; He, X.; Zhou, T.; Qin, T.; et al. Upregulation of PD-L1 by EGFR activation mediates the immune escape in EGFR-driven NSCLC: Implication for optional immune targeted therapy for NSCLC patients with EGFR mutation. J. Thorac. Oncol. 2015, 10, 910-923.

(44) Astakhova, I. K.; Hansen, L. H.; Vester, B.; Wengel, J. PeptideLNA oligonucleotide conjugates. Org. Biomol. Chem. 2013, 11, 42404249.
(45) Lee, J. S.; Song, J. J.; Deaton, R.; Kim, J.-W. Assessing the detection capacity of microarrays as bio/nanosensing platforms. Biomed. Res. Int. 2013, 2013, 310461.

(46) Lamiable, A.; Thévenet, P.; Rey, J.; Vavrusa, M.; Derreumaux, P.; Tuffery, P. PEP-FOLD3: Faster de novo structure prediction for linear peptides in solution and in complex. Nucleic Acids Res. 2016, 44, W449-W454.

(47) Antunes, D. A.; Moll, M.; Devaurs, D.; Jackson, K. R.; Lizée, G.; Kavraki, L. E. DINC 2.0: A new protein-peptide docking webserver using an incremental approach. Cancer Res. 2017, 77, e55-e57.

(48) Li, J.; Xing, R.; Bai, S.; Yan, X. Recent advances of selfassembling peptide-based hydrogels for biomedical applications. Soft Matter 2019, 15, 1704-1715.

(49) Jing, P.; Rudra, J. S.; Herr, A. B.; Collier, J. H. Self-assembling peptide-polymer hydrogels designed from the coiled coil region of fibrin. Biomacromolecules 2008, 9, 2438-2446.

(50) Li, Y.; Chen, C.; Xu, D.; Poon, C.-Y.; Ho, S.-L.; Zheng, R.; Liu, Q.; Song, G.; Li, H.-W.; Wong, M. S. Effective theranostic cyanine for imaging of amyloid species in vivo and cognitive improvements in mouse model. ACS Omega 2018, 3, 6812-6819.

(51) Lakowicz, J. R. Principles of Fluorescence Spectroscopy, 3rd ed.; Springer US, 2006. 